\title{
The Structural Creation of Virtual Power in a Large Network
}

\author{
Dr. Douglas K. PETERSON (Corresponding author) \\ Academics-International.Org \\ 1766 Avery Plaza Street, Ft. Collins, COLORADO, USA \\ E-mail: dpeterson@academics-international.org \\ Dr. XING YuanYuan \\ Liaoning University \\ Shenyang, LIAONING, PEOPLE'S REPUBLIC OF CHINA \\ E-mail: XINGyuanyuan@lnu.edu.ac
}

Received: July 13, 2020 Accepted: Oct. 8, 2020 Published: January 1, 2021

doi:10.5296/jmr.v13i1.17348 URL: https://doi.org/10.5296/jmr.v13i1.17348

\begin{abstract}
Our conventional wisdom indicates that because of their spread-out nature, performance networks for large projects are bound to experience perfect power diffusion where no one player is likely to gain hegemony over others. We might be wrong about that. It is possible that oligarchic network positioning and influence may emerge (Ansell, Bicher, Zhou, 2016) as political considerations and dominate the more traditional bureaucratic ones. These are applicable for decisions that involve an allocation of resources, adoption of technology, design of control systems, and methods of project appraisal (among others). While considerations for these seem to be dedicated to the limited set, there is a large shortage of work on the application of power in the larger context of networks and very large initiatives (VLI) that may be found in customs, trade, economic, and political unions. This can also be found in any political integration or economic integration projects, for example in the Belt and Road Initiative (BRI). The contention is that exchanges of power in formal regulated structures may be predictable, it is the informal and unregulated condition that influence performance of integration. This paper focuses on the structures for minority control and suggests these strategies to influence a network come from the influence of nodes and edges of the network, and not from top down control.
\end{abstract}

Keywords: Belt and Road, Euler, network control, node control, edge control, political control 


\section{Introduction}

This article makes its contribution by discussing virtual power in organizational networks known as the VLI, or the Very Large Initiative. For the purposes of this article, a VLI network is simultaneously a formal and informal organizational structure, designed to create a multilateral effort of participants who are influenced emergent, steady, or random demands (Smith, Xie, 2015; Watson-Manheim, Chudoba, and Crowston, 2002). This type of networked virtual organization is tough to describe in a two or three-word soundbite. It's very tough to nail down in definition. These networks are ethereal, virtual, and established through nodes and edges. These have working direction. They are virtually omnidirectional, yet there are simultaneously multiple visions and outcomes, where control/power comes from the ability to leverage the direction, height, flow, and width of that object. The contribution of this paper is that networks and members can leverage power through the control of only a few edges or connecting nodes of a network structure. See Figure 1 for the messy state of the VLI perfectly competitive network. Basically, there is no home base, just different volumes of information going through nodes (the circles) and edges (the lines between them). By the way, these networks are never static, the're quite dynamic.

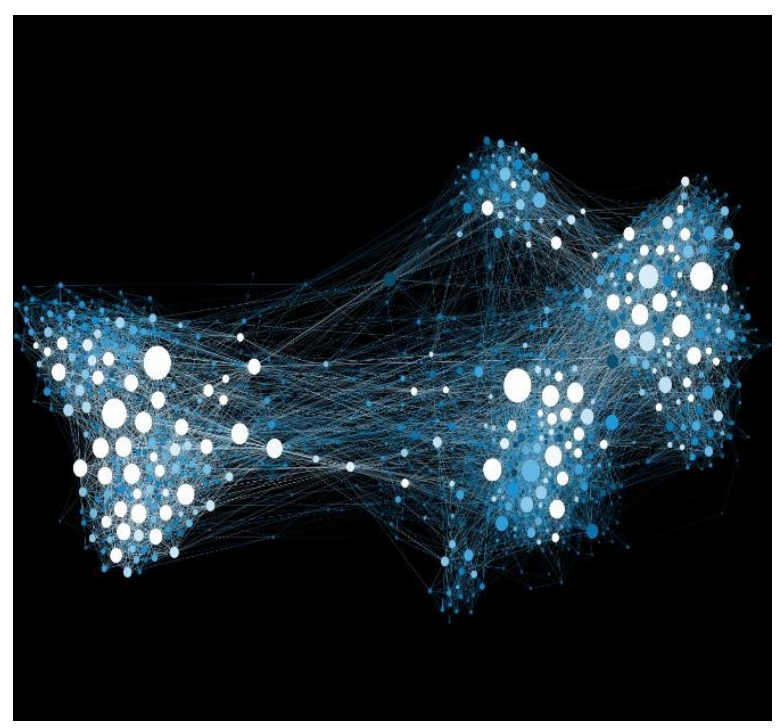

This Photo by Unknown Author is licensed under CC BY-

Figure 1. The VLI Network.

This work describes process and action to explain, predict, and control virtual power differentials

(Blondell, Guillome, Lambiotti, 2008) where position is something that "could" be existing in a virtual and electronic world but probably better explained as task, task need, and task positioning to create relative positions and power dynamics. This type of organization is relativistic in its organizational structure and focus because task, authority, uncertainty, and leverage are interpreted and applied in differing parts of the network. In this paper, the VLI under consideration in this paper is named the Very Large Initiative (VLI), and the example for most of this work comes from the Chinese Belt and Road Initiative, or BRI. 


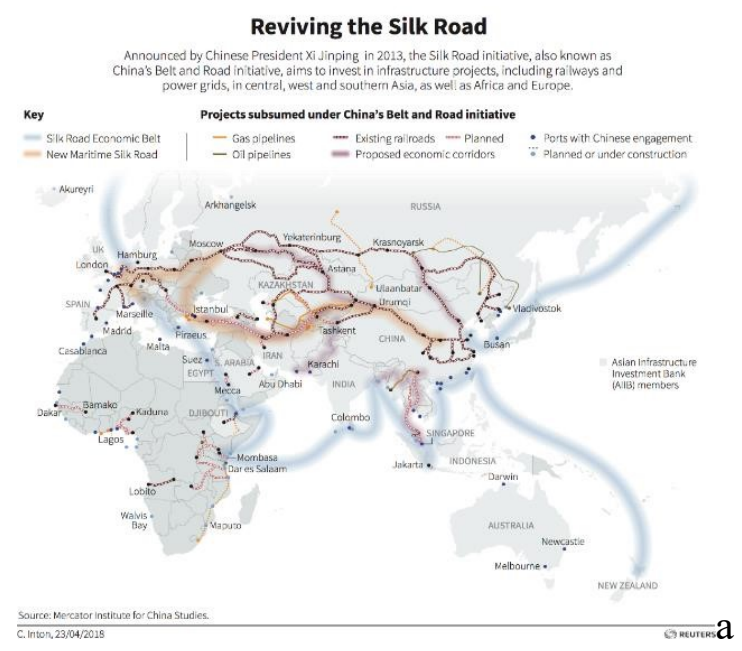

Figure 2. BRI network mapping. Source: World Economic Forum/RAND

For those who should know, the BRI is an initiative proposed by the Chinese to establish an extrastructural wide and deep organization by creating land routes from Xi'an to Moscow, Rotterdam, central, southern, and eastern Asia, and selected countries with deep water ports in Africa.

The economic impact of the BRI is impressive. This $\$ 7$ trillion project, upon completion and growth, will impact a very large portion of global GDP, world middle class, global transportation logistics, and trade opportunities in all industrial groups on four continents. It will shorten land transport time and cost by half, and provide raw materials, finished goods, agricultural products and industrial machinery to areas with more than 1 billion people and it will establish protected corridors on land and at sea.

Some studies suggest issues that require further development in the VLI regarding the route, orbit, and interdependence and practical uncertainties (Sniezek, May, Sawyer, 1990). While there seems to be a wealth of academic research and writing from the trades, there is very little on the power dynamic that comes through VLI and network operations (Chao, Wu, Jain, 2003). This paper is most likely original in the management and influence on networks, especially regarding political, cultural, or economic power (Milo, Shen-Orr, Itzkovitz, Kashtan, 2002). A necessity however, is the development of technology for coordination and communication regarding network positioning and control (Breitkreutz, Stark, Tyers, 2003).

Indicative of discussions regarding BRI is work on political risk, the technologies of connectedness, the measurement of routes and energy consumption, security along the belts and roads, geopolitics and potential conflict, and financing options throughout the initiative regarding debt, equity, and performance structures. Fiscally, the BRI is expensive. There will be countries, governments, industries, and peoples who cannot afford the infrastructures to avail themselves of the project's benefits, they will be offered help from the IMF, the World Bank, the Asian Infrastructure Investment Bank, the Chinese government, and interested governments at all levels. Theoretically, the larger players should control the content and process of the initiative. This paper will suggest that smaller players may gain more control of 
a network through technological sophistication. In doing this, there is the possibility that small economies can leverage virtual position to gain control of network flow and logistical position. (Pennings, 1975).

The levels of analysis presented in the literature and as seen by the sophisticated observer are also impressive. These analysis levels operate in the gamut from the environmental, continental, regional, country, and industrial levels. Coordination of the BRI will be an exercise of human, but also network coordination with real and virtual power being exerted.

Virtual position is defined as the control of uncertainty and power that comes with it. One is in a virtual position when they have control of time, money, machinery, logistics, and most importantly the allocation of human time. As part of a thought exercise, ask yourself who or what may have control over schedule, resources, meetings, or time. For academics, the greatest virtual position lies with the office manager, the department chair, and to some extent now, the student who is willing to raid the university hierarchy rather than settle disputes locally. For a Provost, the executive administrator controls all time and appointments. For the faculty, the student assistant controls graded papers, or even white board markers. This is the nature of virtual position. There is very little here in a formal organizational structure. Most organizations don't describe themselves by who really has power. They describe themselves in a political statement $d u$ jour. Virtual position has been traditionally discussed as a within-organizational phenomenon where the control of critical uncertainties can be found among players outside of the normal hierarchy. Should the cooperation through connectivity work, that's great. If not, it will be control of weak parts of the network, introduce uncertainty, and gain further control as a network adapts.

We should understand how the much larger organization, the VLI type, can experience virtual position control, and power. Literature on VPs tends to look at a formal and informal organizational structures.

This is very different than what this paper explores in the positioning of network flow, depth, or utility. These are all things that are difficult to assign to one person, see, or touch in proximity. Is it possible that virtual positioning can be code, or app based? Yes. Could it be likely that code adjustment and hacking could give a virtual position both within and outside of the network? Yes. In this case, with more than 120 countries signing onto this project with the expectation of infrastructure development, economic growth, human development, and wealth enhancement, the topic of legal and extra-legal connectivity and control can have a large impact (Doz,1996).

Readers might be asking whether the virtual position constructs exist only in hierarchical structures or matrices. This paper doesn't claim that hierarchical structures or matrices control authority, and therefore decisional power. That's something the structuralists, neo-structuralists, or linear perspectives didn't see.

Rather, it claims that the control of uncertainties and decisions in the virtual isn't linear at all. This is the antithesis of linear. It is indirect, dimensional, circuitous, networked, and chaotic. Some would say this is invocative of a multilayer game of chess where multiple directional, 
lateral, forward, or backward moves are planned and where changing scenarios are common because of the multidimensionality. It is where the control of this game can be far, far from the expected positioning. In order to explain, predict, and help control this behavior in a network, we need to propose a conceptual and mathematical construct that requires combinatoric, chaos, and network theory.

\section{Virtual Position in a VLI}

Virtual positions involve three or more discrete entities at differing positions within or between network structures for information or decision making. These can be at any level of analysis from the person based dyadic/triadic to the group, VLI, network, and environmental level. While it is correct to assume this could be a within-organization issue, one of the foci of this paper is that our studied phenomenon is equally valid between VLIs and moderated by cultural convergence, cultural divergence, the corruption, bureaucratic inertia, or activism.

As indicated, work on virtual positioning is generally applied within single organizational structures where power is concentrated toward control of intangible vital resources. This is done within existing organizational structure and reflects what we might expect: an executive makes a firm and powerful decision that others follow in implementation. The decision is focused downward, and compliance is required. Virtual positioning predicts something different. That is, the center of virtual power, and therefore inter / intra-organization power is likely away from hierarchy, it is somewhere else. It is very likely to not be within what we would call legitimate, reward, coercive, or resource power. These are known as positional sources of power. What might be interesting is the emergence of personal power or virtual power in the control of virtual positions and certainly is a topic that should be explored.

The interesting question arises when we ask about the sources of virtual power (Mackenzie, 2018). Remember, our levels of analysis are no longer within organizations, or strictly related to business organizations. The organizations we examine here are concatenation of many organization types from the small or corporate business organization, to the non-profit, to the non-governmental, the academic, as well as multiple levels of government from the State to the region, and the municipality. The Table 1 below cites a few examples of French and Raven power sources and their potential. 
Table 1. Bases of power in network.

\begin{tabular}{|l|l|l|l|l|}
\hline $\begin{array}{l}\text { Personal } \\
\text { Power (PP- }\end{array}$ & Referent & Expert Enact* & Information & Connection \\
\hline Business & Benchmark & Consultant & $\begin{array}{l}\text { Competitive } \\
\text { Intel }\end{array}$ & Personal networks \\
\hline Non-Profit & Segment & Org/Board. & Referents & Project partners \\
\hline Government & $\begin{array}{l}\text { Us/them } \\
\text { comparison }\end{array}$ & $\begin{array}{l}\text { Opinion } \\
\text { leaders/base }\end{array}$ & $\begin{array}{l}\text { Legislative \& } \\
\text { External } \\
\text { Input }\end{array}$ & $\begin{array}{l}\text { Public and ab } \\
\text { Db* }\end{array}$ \\
\hline NGO & Funding & $\begin{array}{l}\text { Subject } \\
\text { Experts }\end{array}$ & $\begin{array}{l}\text { Peers, } \\
\text { workshop }\end{array}$ & $\begin{array}{l}\text { Network in } \\
\text { between projects \& } \\
\text { peers }\end{array}$ \\
\hline Academic & $\begin{array}{l}\text { Peer } \\
\text { Aspirants }\end{array}$ & $\begin{array}{l}\text { Peer } \\
\text { Academics }\end{array}$ & $\begin{array}{l}\text { Databases and } \\
\text { i-Peers. }\end{array}$ & $\begin{array}{l}\text { Db, email, visual, and } \\
\text { conferences }\end{array}$ \\
\hline
\end{tabular}

PP-VP $=$ Personal Power - Virtual Power, $\mathrm{Db}=$ Database.

We tend to think of organizational power as a process of position, seniority, expertise, and perhaps money. When we have power, we probably learned it is better to give than receive or use power rather than have it used. In the VLI, power really doesn't have a shape, and most likely doesn't come from predictable places. It is likely, however, to come from controlling the levers of uncertainty of personal, referent, expert, information, and connection power. Given the list table above, power might emerge informally through the control of a work characteristic, a referent's message, an expert's access, or information control and distribution as a democracy, dictatorship, or oligopoly at the same time (Ansell, Bichir, Zhou, S 2016). Following is a revision of the previous table with how-to suggestions. See Table 2 for revisions. 
Table 2. Reframe Table 1

\begin{tabular}{|c|c|c|c|c|}
\hline $\begin{array}{l}\text { Personal } \\
\text { Power (PP- } \\
\text { VP) / Enact* }\end{array}$ & Referent & Expert & Information & Connection \\
\hline Business & $\begin{array}{l}\text { Shift benchmark } \\
\text { or referent. }\end{array}$ & $\begin{array}{l}\text { Re-interpret } \\
\text { content or process } \\
\text { or resources. }\end{array}$ & $\begin{array}{l}\text { Switch frame, } \\
\text { path, node, edge, } \\
\text { code. }\end{array}$ & Contaminate \\
\hline Non-Profit & $\begin{array}{l}\text { Introduce new } \\
\text { segment. }\end{array}$ & $\begin{array}{l}\text { Assert Board's } \\
\text { intentions in new } \\
\text { way. }\end{array}$ & $\begin{array}{l}\text { New referents, } \\
\text { new peers, } \\
\text { referent } \\
\text { discredit. }\end{array}$ & $\begin{array}{l}\text { Connection } \\
\text { mechanism. }\end{array}$ \\
\hline Government & $\begin{array}{l}\text { Different } \\
\text { governments, } \\
\text { processes, or data } \\
\text { interpret. }\end{array}$ & $\begin{array}{l}\text { Competing sets of } \\
\text { experts. }\end{array}$ & $\begin{array}{l}\text { Internal data } \\
\text { without external } \\
\text { influences. }\end{array}$ & $\begin{array}{l}\text { Slower, faster, } \\
\text { newer } \\
\text { technologies. }\end{array}$ \\
\hline NGO & $\begin{array}{l}\text { Change to peer, } \\
\text { process, } \\
\text { competitive } \\
\text { benchmarks. }\end{array}$ & $\begin{array}{lr}\text { Change } & \text { levels of } \\
\text { analysis } & \text { from } \\
\text { subject } & \text { to } \\
\text { something else. }\end{array}$ & $\begin{array}{l}\text { Different data } \\
\text { sets or access to } \\
\text { app attributes. }\end{array}$ & $\begin{array}{l}\text { Set network access } \\
\text { and directional. }\end{array}$ \\
\hline Academic & $\begin{array}{l}\text { Referent groups, } \\
\text { disciplines. } \Delta \\
\text { coffee recipe. }\end{array}$ & $\Delta$ funding rules. & $\begin{array}{l}\mathrm{Db} \\
\text { application } \\
\text { access. }\end{array}$ & $\begin{array}{l}\text { Add or subtract } \\
\text { network } \\
\text { requirements. }\end{array}$ \\
\hline
\end{tabular}

$* \mathrm{PP}-\mathrm{VP}=$ Personal Power - Virtual Power, ${ }^{* * \mathrm{Db}}=$ Database.

It is conceivable that this analytic can apply to other areas of virtual reality. For example, imagine the influence that could accrue to the control of task and task structure, to the assignment of dyadic, triadic, quadratic, or googled influences who are interconnected and working to influence group structures, flow, politics, geography, and/or governance.

Of great interest to us is whether a formal structure of the roll-out goes from East to West, or whether there is another more plausible reality. The best rollout culturally is outward in, not origination out. One very unique study (Fu, Chen, Xue, 2018) performed a factor analysis of likely variables predicting acceptance and implementation of the VLI. What this study found was that implementation may be more effective outward in, rather than in a straight line out. The reason? The predictors were intangibles like cultural distance, where closer cultural distances would face lowered uncertainties to control. See Figure 3, 4.

Standard Rollout Assuming Here - There Questioning Cultural Enactment: Rollout There Here 


\section{$\Lambda$ Macrothink}

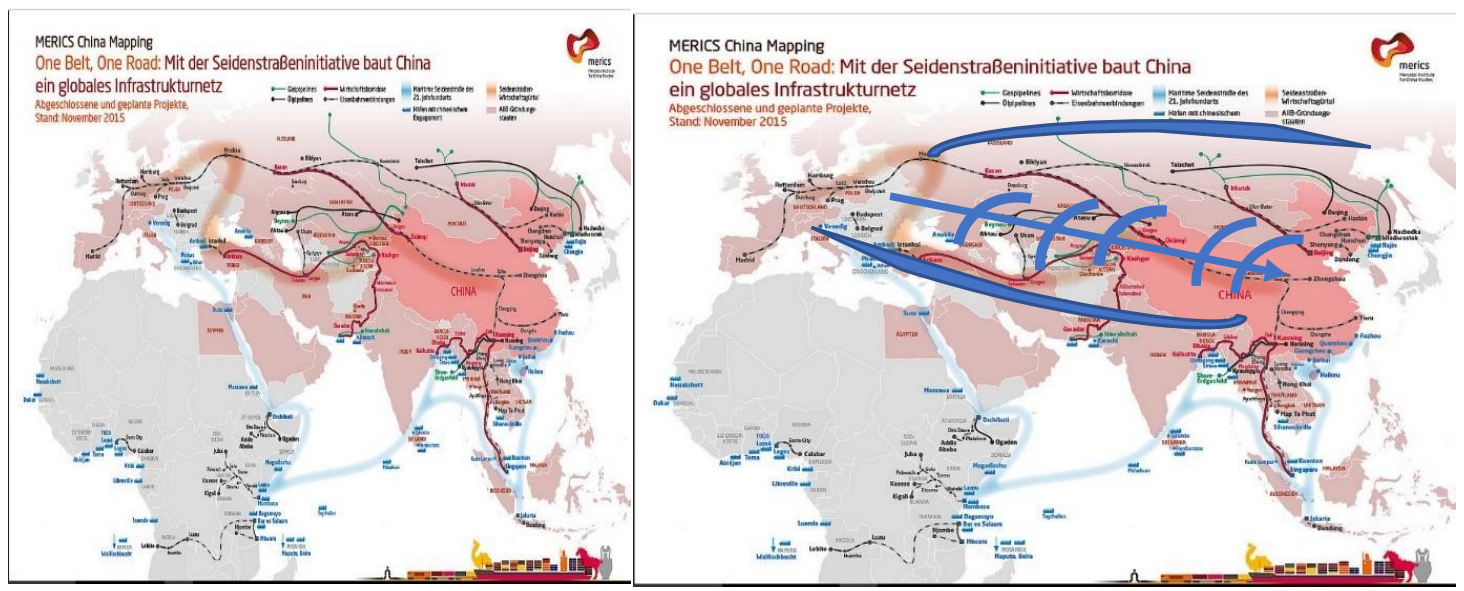

Figure 3. Inward Out: More Control?

Figure 4. Outward In: Better

\section{Consistency?}

Examples within that paper and construct formation, go just a bit further in explaining VLI power relationships at the larger level of cross national and cross-cultural interaction. The model here does not portend power equivalence among players - quite the opposite! It implies that power relationships can come from anywhere, and it implies there are potential leveling strategies. The models assume that different organization forms from differing inter-organization levels and locations that work together on related task process and commonly have competing virtual positions that are invisible to the other. In management theory, we believe in linearity where all jobs have reporting relationships, identifiable and discrete tasks, and clear decision making at the right part of a hierarchy. Moving just a bit beyond established formality, we should recognize emergent processes in organization structure where there are formal, regulated positions in organizations as well as emergent and unregulated virtual positions. Typically, regulated/formal virtual positions take sanctioned forms of conferences, committees and the task force. They are assigned, structured, and charged by formal/regulated authority. In other words, "requires and establishes, care, and support of a set of tasks with reporting relationships in hierarchy and the assumption of (relative) longevity".

The nonregulated/emergent contains operations that are neither rationalized nor regulated in a formal structure or design. The primary indication for the unregulated/emergent is that where inputs leading to informal changes occur at a more rapid rate, how about informal communication via social media, for example, Twitter. The virtual position is the one that leads to control of the unregulated, AND control in the formal structure. That is, by using virtual position to control the unregulated, we coopt regulated processes. Each virtual position involves taking control of key processes and using them for possible leverage of that task process on others. Each virtual position participant has access to information, structures, decision processes and the possibility of influencing other processes and structure where each 
virtual position can possibly establish growing unregulated, entropic, or inertial process (Keohane, 2002; Baligh, 1986).

\section{A Little Depth in Power}

Power is the ability to put activity and influence into motion. Political scientists, sociologists, and organizations theorists have had an interest in the topic of power in organizations for decades. In a review of existent literature on power, it appears there is no general agreement on what organizational power and influence is, how it is constructed, what its impact is, and how it flows toward the environmental, competitive, industry, organization, group or individual levels of analyses. Most analyses are contingent in their definitions and therefore focus on situational levers and assertions these levers are both applicable and generalizable. As a point of fact, it is also generally not agreed how power flows within organization, between organizations of all forms, or within the greater environment.

What does seem clear is that the creation, shaping, distribution, and use of power in VLI is a multifaceted construct, and like leadership theory, it is very difficult to center into a consensus. What's more, identifying constructs and application of power or leadership existing between formal/informal regulated/unregulated entities, or in larger groups, is a huge proposition,.

In the VLI, there are difficult propositions to consider. For instance, is power to place activities in motion a dependent or independent variable. Is it a situation? Is it a process or task ownership problem? Is it a resource control issue? Is it a toolbox for ad hoc influence? Is it a leverage tool? It is uncertain as to the outcome of power relationships, and whether they can be useful to the collective or individual players.

Let's build upon our conceptualizations of power and leadership, but not as something that depends upon legitimacy or expertise. The conceptualization of power here is in the control of key variables that others need for their work or lives and whether how control is obtained. The conceptualization doesn't depend upon any of the power variables or position authority we might read about. This conceptualization rarely depends on formal organizational position. Once again, it arrives through the control of an uncertainty, for instance the control of a few lines of code, route for resource distribution, logistics mechanisms, timetables, or bureaucratic non-knowledge.

Potential theoretical bases for these explorations reside in resource dependency and critical contingency (Van de Ven, Drazin, 1984; Donaldson, 1976; Schoonhoven, 1981; Donaldson, 1999). Both concepts seem to neglect tasks of organizations in favor of the leverage that resource dependency and contingency concepts explain. For example, resource dependency and critical contingency predicts outcome, but not the antecedent processes, leverage, or the controls that created it. It's the outcome of dependency and critical contingencies in which there is interest, not the contingencies, interdependencies, power struggles, and positioning for uncertainty control that predicts the resource dependency and presents the critical contingencies. It is exactly these contingencies, interdependencies, power struggles, and positioning we seek to explain and exemplify. 


\section{MlMacrothink}

Journal of Management Research

ISSN 1941-899X

2021, Vol. 13, No. 1

The purpose for including data from social media is to identify social vectors and the lexicons that are essential to capturing convergent and divergent socio-characteristics through information technologies. In each case, they apply a process orientation directly to the identification, explanation, prediction, and control of the backend process arenas and the power struggles that identify arenas where they play out. These arenas are called virtual position. They identify the task processes that cut across normal organization logs and identify the uncertainty control in processes and therefore the power dynamics that are independent of formal organizations' structure.

\section{Terminologies}

Our key constructs are position, task, task gap, process, job, forum, and virtual position. See the following table:

\begin{tabular}{|l|l|}
\hline Construct & Definition \\
\hline Virtual Position & $\begin{array}{l}\text { An amalgamation of task or process that is performed or supervised } \\
\text { either in place or in a virtual attendance pattern. Traditionally, people } \\
\text { perform these as jobs discrete jobs but in reality may not be that way at } \\
\text { all. Examples? Teacher, Principal, Administrator. Virtual manager, } \\
\text { blogger, systems security engineer. }\end{array}$ \\
\hline Virtual Task & $\begin{array}{l}\text { An activity where some activity of a position is accomplished. Writing } \\
\text { reviews, managing applications, data entry, security monitoring, } \\
\text { systems entropy. }\end{array}$ \\
\hline $\begin{array}{l}\text { Virtual Task Flow } \\
\text { and Gap }\end{array}$ & $\begin{array}{l}\text { Creates uncertainty in the activation of authority where tasks, positions, } \\
\text { and decision making is in a vacuum. }\end{array}$ \\
\hline Virtual Process and & $\begin{array}{l}\text { The process of performing a task whether ascribed or proscribed. } \\
\text { Operations procedure. This would be very tricky to monitor or enforce in } \\
\text { a virtual world. }\end{array}$ \\
\hline $\begin{array}{l}\text { Organizations } \\
\text { Positions }\end{array}$ & $\begin{array}{l}\text { The amalgamation of tasks into processes and into positions that are } \\
\text { combined. }\end{array}$ \\
\hline $\begin{array}{l}\text { Convening } \\
\text { mechanisms } \\
\text { described as they proscribe tasks or positions. Formal, informal, or } \\
\text { virtual committees. }\end{array}$ \\
\hline $\begin{array}{l}\text { A virtual position has three or more positions involved in a task process, } \\
\text { where interactions happen in a convening mechanism. }\end{array}$ \\
\hline
\end{tabular}




\section{The Nature of Virtual Positioning in a VLI.}

Theories of distribution of power in VLIs vary in their ability to explain, predict, and control power and influence phenomena. It does seem to be clear, however, that assumptions of VLI power stem from dependence of A toward B, creating an imbalance of valued resources or controlling a critical response to an VLI issue because of political or perhaps other agendas.

Dependency theories seem to leverage these relationships and deploy them in all manners of dependent and independent variables, for example, dependency on VLI hierarchy, budget, expertise, legitimacy, or the great-man theories of charisma. Critical contingencies arise from more sources, for instance, VLI positioning roles in the environment, VLI or industrial strategy, characteristics and product / divisional mix, key technologies, efficiencies in a value chain, quality control efforts toward current fad, and environmental regulation. There seems to be a shared assumption that VLI power is based on a relationship between social factors that produce degrees of dependence in a chaotic virtual system.

These assertions raise another assumption that power is applied within an VLI, or between VLIs as leverage and dependency. Critical contingencies approaches pursue something different in that the perspective of the distribution of power in VLI leads to the view that political considerations dominated the more traditional bureaucratic environments. Applicable to these assumptions are allocation of resources, adoption of technology, design of control systems, methods of performance appraisal, and many other VLI realities. While these seem to be dedicated to the limited set, there is a shortage of work on the application of power in the larger context of networks and the VLI found in the large customs, trade, economic, and political unions. These can be exemplified in the regional integrations EU, MERCOSUR, ANDEAN PACT, ASEAN, AND APEC, but not measured and predicted. It is here where the formal and regulated position and task process is accomplished. It is also here, in the absence of formal regulation in a very large system where there is strong potential for formal unregulated conditions that create ad-hoc performance of integration, but also enactment of informal or virtual power relationships.

This is a nuanced subject. Some VLI networks are predictable. We can explain, predict, and control action in them. We also know that very large VLIs like the UN, the WTO, an international military alliance any VLI that depends upon a small and general technical core and large numbers of subcontractors becomes less predictable and more entropy oriented as partners in wider and wider geographic regions are added. One sort of private enterprise that also depends upon a general and subcontract relationship is the construction firm, a type of VLI that is of critical importance in the BRI as infrastructure becomes built. All of these VLI types have their own power dysfunctions. Within and between these VLIs and becoming potentially worse to the extent of geographic and cultural dispersal comes the combination of ad hoc (unregulated) and formal, regulated decision making, variances of which cause plays for uncertainty through information asymmetrical environments. Fortunately, there is some research (but not enough) in relationship to what the right size is for a network to manage its virtual positions and power. 


\section{Variables That Reduce Uncertainty}

There is another relevant question beyond size, and that's whether there is a mechanism to align complex environments and partners. This isn't a benign proposition, and in fact due to the high complexity and capital investment from varied sources with varied objectives seems that a coordination mechanism is possible, for instance with a very large integrated network or even a closed social media application. This could provide connectivity, but also a very large forum for both regulated forums and unregulated conversation and innovation ideas that are not quite ready for release but need coordination, data, and information mining. Another highly relevant question is whether there is an optimal size for network functionality and where both nodes and vertices should be, and in how many configurations should be created to close operations and innovations circuits. This is not a benign question either.

Given the size and complexity of the VLI, and the difficulty of providing governance and setting a continuous improvement basis for course correction, it might make sense to follow the lessons involved with the management of the larger economic and political unions, the VLI consortium, or the large alliance. The EU for example, and a general European governance body. Other bodies do this through strategic alliances which create structures to manage organic growth, create proximity and quicken speed to market, share costs, and facilitate transnational access. These alliances are found in government and industrial networks for finance (NASDAQ), consumer products (Coca-Cola or Luxottica), for communications (any social network, but especially WeChat, WhatsApp, or Facebook), or coordination of action and plans (ASEAN, NATO, SADC).

\section{Application of Power in Virtual Positions}

The literature on power, especially the neo-structural and critical contingency schools, built upon mutual dependence and the control of uncertainty has a basis for maintaining and creating dependency. The concepts of dependency and uncertainty employed in these studies are unclear; of interest is the social judgement of a third party on the needs and goals of other actors. For example, if one assumes that State, individual, or VLI actor 1 desires more income and higher rank and actor 2 controls the level of income and promotions, then it is plausible to assume that the person desiring more will be frustrated if the only leverage applied is in regulated forums (Castells, 2010).

The situation of dependency is confounded because each actor has some flexibility and how the commodities are distributed. Will the target person receive a raise if he complies? Will the target do more than is desired by the controller if the controller grants a promotion? Will not both the controller and the target practice deception and opportunism for managing mutual dependency? In this case, we have a gordian knot of complex and inner woven beliefs, goals, dependency, and deception. It is difficult to see any feasible methods for untying the knot with the existing ideas and methodology that the traditional managerial lexicon provides. Perhaps if we change how we look at the phenomenon of power, we can then develop new lenses which improve analysis and remedy. It is the notion of virtual positioning in interdependencies that promises to untie a knot. 


\section{Mll Macrothink}

Journal of Management Research

ISSN 1941-899X

2021, Vol. 13, No. 1

One solution is to recast the issues in terms of the uncertainty associated with VLI and environment interdependence. It helps to think of a natural hierarchy of the degrees of inner dependency uncertainty. In the table below, zero level occurs when every aspect of interdependence is well known and understood the task process, as does the role of the die has known properties. There are only minor variations. The interdependencies are well specified all the way from the market to the machine operator.

Now, let us consider a reality of uncertainty control doesn't work beyond the formal level. Now consider what we know as an VLI reality. The State doesn't control the uncertainty at that level. The executive cabinet assistant or bureaucrat does. Even more, the applications manager or the security engineers.

Consequently, the metaphor of mutual dependency, while appearing as a first-order diagnostic heuristic, is inherently oversimplified. The oversimplification of the reality of interdependence is combined with assumptions of tasks process stability and regularity. It is also encouraged by statistical procedures relying on independence assumptions and descriptive data pertaining to the only selected facets of actual task process for instance level of next year's budget. The results and conclusions, while interested and thought-provoking are suspect for example what size does the budget really mean in most cases the size of the budget determines what personnel are needed and what task processes will be performed. That's the fight over budget is a surrogate for control of the interdependence uncertainty.

The next step is to examine how one can identify some arenas of power in order to study power struggles in VLI. This brings us back to the description and analysis of virtual position.

The notions of interdependencies that were introduced in the previous two sections provide for the prospects of a new lens. There is a technology and methodology for describing task process and their interdependence. There is the beginning of a technology for understanding task process resources interdependencies. There is a technology for describing positions and structures based on these ideas can help us define explicitly the interdependencies and forums existing in any VLI.

The first condition for the use of power is interdependence, which can be defined as a situation where whatever happens to one player in an alliance affects what happens to others and is likely to be requisite for conflict. Consequently, reducing excess interdependence is a means for reducing conflict. Despite the trite statement, concepts and practices of interdependence remains fluid.

There are some definitions that require elaboration here. First, there is a process. Independent of outcome, the process is a time-dependent sequence of structured governed by a rule called the task process law. Each task process law has five components. These are entities involved in performing the process, the concepts and knowledge elements used to describe the steps in a process, the relationship between every pair of these elements, the links to other processes, and the resource characteristics of each element.

Task process aggregation describes the descending detail of tasks. Groups of tasks processes divided into bundles which break out into groups of tasks process and finally modules with 
constituent activities groups of tasks process is divided into bundles, the bundles into modules, and finally the modules have constituent activities.

The description of all tasks process this organization is called The Logic. Structure. Most VLIs have thousands of activities. A system for labeling and organizing processes has been in use according to network audit technologies that are in existence and under development. In the technology, the logic can be displayed as a 3-D diagram or as an extensive listing. The logic displays the task process in a dependency and depicts changes of task process interdependencies. That's the VLI logic can be used to specify task process interdependencies. For the VLI, databases of tasks processes, when coupled with computer application technology yields the ability to both update task process, task process performance, and task process distribution, which in turn can allow both dependent and independent level analyses leading to a design and redesign of flow.

\section{Characteristics of Task Resources}

Actual VLIs are rarely the same as their VLI structure. Therefore, it is not a safe assumption to rely on the accuracy of official information to describe an actual organization of this type. There is another complication. While the VLI structure may represent who has the formal process or position authority, it does not describe the reality we need. Most published studies of power rely on official documents, questionnaire items, and gross indices of interdependence. A great deal of the research on the BRI we read now bases itself on that. Consequently, the results and interpretations are highly suspect. They do not get inside deeply, and they do not specify the critical details of who, what, when, why, and how. It does not describe how involvements and interactions occur, and it does not describe the genesis of new interactions. It's difficult to understand the actual VLI using such means as structure and how an actual VLI operates differently than what normative descriptions believe.

\section{Authority}

Task gaps come with formal authority. Task gaps create uncertainty in the activation of authority for they present process vacuums and a resolution uncertainty. In other words, task gaps excess VLI interdependence as people reach out to determine leadership in the use of scarce resources that characterize the exercise of power.

Ad hoc committees, standing committees, and task forces appointed to resolve task problems are considered regulated because there is usually a person in charge, the membership on the committee is appointed in a set of specific charges have been made. Committees, standing committees, and task forces resemble collateral VLI forms which lie outside the normal organizational structure and probably outside of an actual VLI. Generally, regulated forums are constituted to reduce independence, but they may wind up making it worse.

There are also unregulated authority task gaps which abound in VLIs facing rapid change. Such changes include new regulations, new technologies, new conception competition, plugging gaps created by employee turnover and succession, and informal struggles for control of the VLI. Various members of the VLI get involved with these issues. They are unregulated 


\section{Macrothink}

Journal of Management Research

ISSN 1941-899X

2021, Vol. 13, No. 1

because there is no formally designated person in charge, no officially appointed committees and no specific assigned goals.

The regulated bodies (committees, standing committees, and task forces), and the unregulated ad hoc bodies are called virtual positions. It will be shown that many crucial VLI issues are handled by unregulated virtual positions which create pressure on structure along with the means for resolving task gaps. This is the virtual position where power plays out. Committees have long been recognized as a way of exercising power, but the underlying cause of their existence is habitually ignored. The phenomena of authority - task gaps and virtual positions (plus the technology for uncovering them) adds to the capacity to analyze VLIs especially with the enactment of power.

Suppose that the VLI logic has been defined for an VLI at a certain date and then reorganized at a future date. This would be a measure of task process stability could be defined as the ratio of number of tasks processes with no change and the union of a set of task processes with both dates. Additional task processes, lowered stability, and deleted task process all portends decreased ability. Now suppose that we can also examine the regularity at the performance of tasks processes. A task process is regular if it is performed daily. One can construct an index of decreasing regularity based on what fraction of time it is performed. A corporate usage index would yield a measure for the expected regularity of its tasks processes as a sum of the regularity of each task process.

The traditional management literature is adapted to these assumptions of stability and regularity, however most VLI are unstable. For example, new startup and high technology firms are both unstable and irregular. It is most likely that most VLIs in competitive or fluid industrial operations have a degree of instability and probably find themselves with higher degrees of uncertainty, great propensity for architectural entropy and therefore has terrific potential for unregulated ad hoc bodies. Innovation comes from these activities, but the power and influence structures have higher frequencies. This can be compared with large bureaucracies which are often the blend of stable, regular parts and relatively unstable, irregular ones. Finally, to the extent that firms are neither stable nor regular, the importance of being able to study regulated and unregulated forums allow us to see the virtual nature of power application that doesn't come from an established hierarchy. Consequently, we need to be able to probe more deeply into VLI in order to understand the dynamics of power. 


\section{Formal VLI Architecture}

\section{Routes of the China-proposed Belt and Road Initiative}

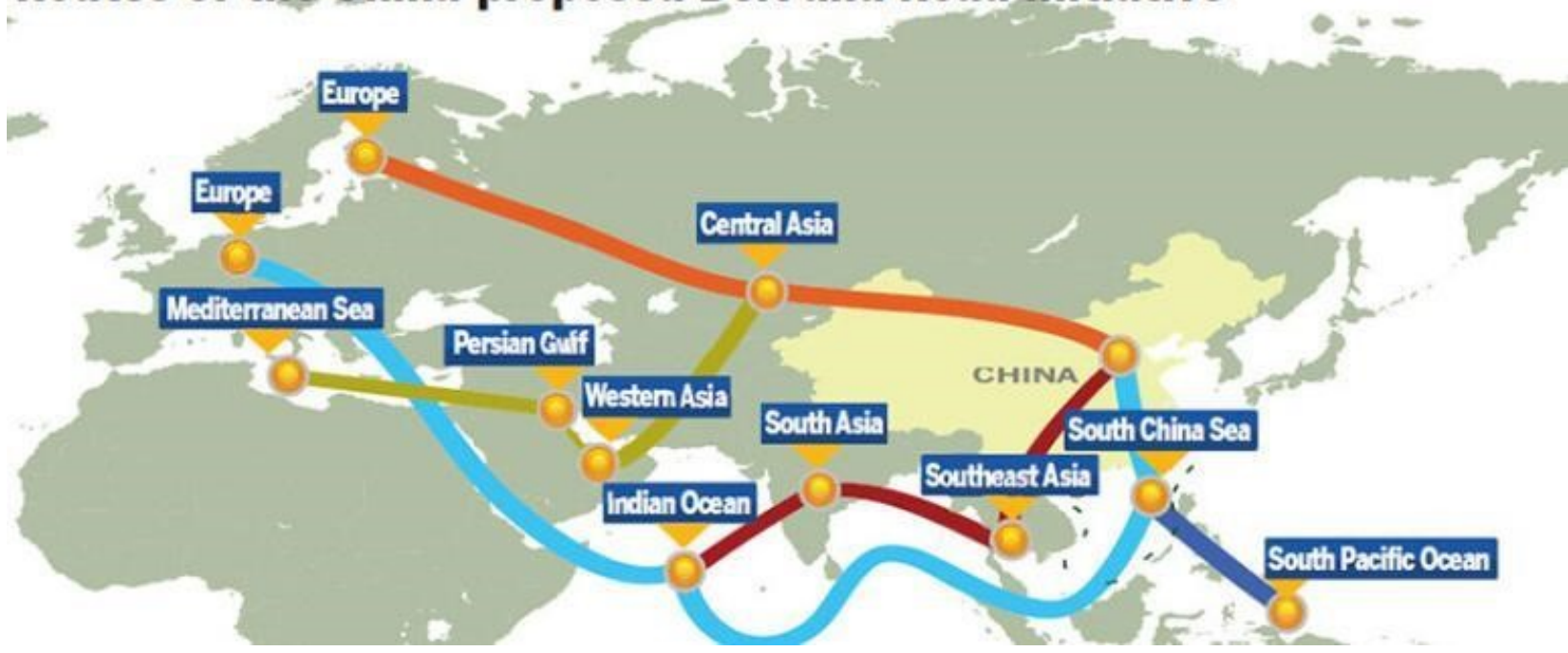

Chart 1, Chart 2. Virtual position and Power / VLI Responsibility and Grouping Charts

A VLI Set Chart: Chart 1 and Chart 2, where Chart 1 is China outward. Chart two is the mixed hierarchy where any country can control an uncertainty or several) at the same time as others, thus gaining some power in the system. Now consider what we know to be reality, as has been my experience. It is chaotic, non-orderly, messy, and subject to uncertainty in virtual power relationships. 


\section{Routes of the China-proposed Belt and Road Initiative}

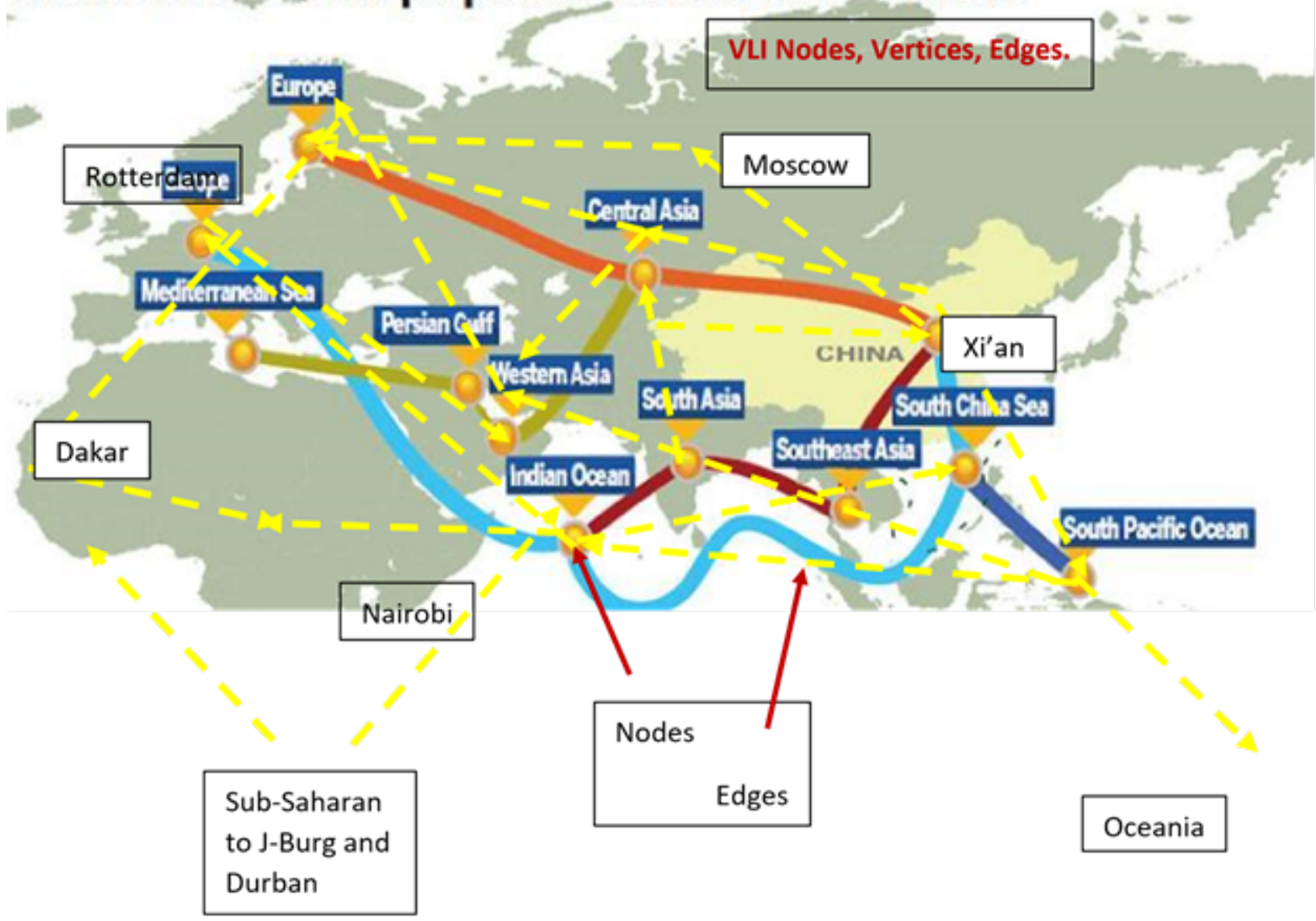

An org chart shows the chain of command for every task process from the board of directors down to the machine operator. The chart is the primary document for identifying interdependence among positions and task processes. It is a flexible tool for diagnosing structural and process problems and for understanding the details of VLI change, and new roles. The level of task process aggregation can be expanded or shrunk according to the need of the analysis. The second chart constructed from an audit shows VLI maladaptation which represents success in the introduction of uncertainty and positions of virtual power. These virtual positions represent a task process as performed by a composite membership.

It has the property of a normal position of including the task processes. But it differs because of the multiple positions involved. Virtual positions are represented in an VLI chart by a junction point with links to the composite number or the actual membership among the positions represents all channel communications where juncture parts show a chaotic nature of actual VLI structures and adapted structure.

Most VLI have multiple virtual positions. They exist whenever there are authority task gaps (Wood, J and Shawe-Taylor, J, 1993). Committees standing committees task forces forums and arenas are examples of virtual positions. Virtual positions also exist whenever an VLI maintains a system for checks and balances where these are defined for major interrelationships and task processes, but not task processes alone. Virtual positions that are 
formally recognized and have set memberships in specific charges are called regulated virtual positions. There are also unregulated virtual positions which arise out of organization change. These unregulated virtual positions are woven with the normal or VLI structure in haphazard, idiosyncratic, and some illegal ways. This is what we look for in a VLI audit. In all cases, the phenomenon of virtual positions needs to be explained in relationship to why they exist, where are they likely to be found, and what impact they have on how an VLI works. Other things we need to know are the dynamics of formulation and absorption where virtual positions are natural phenomenon which form to cope with environmental and internal changes. They are considered adaptive in the short run, but less likely to be so in the middle and longer terms.

\section{Why Virtual Positions Form}

The existence and reasons for authority task gaps help to create the virtual positions involving task process and authority task gaps. The regulated virtual positions are officially sanctioned. They arise whenever authority task gaps generate authority task problems. Unregulated virtual positions are not officially recognized, but nonetheless exist. In these cases, the rise of unregulated virtual positions requires explanation of how unregulated virtual positions reside in authority.

There seem to be two main sources of unregulated virtual positions. The first is change imposed by the environment. This source includes changes such as regulation, technology, and economic or competitive changes. These environmentally induced changes require some VLI adaptation for which, given the existing positions, there is considerable interdependence and certainty. The second source comes from internal initiatives to change responsibility of existing positions without rationalizing new interdependencies. A good example is where VLI leadership convinces officers to get involved in unrelated functions. In all cases, the additional load is not likely to be sustainable.

\section{Dynamics of Virtual Position}

Both sources of unregulated virtual positions involve ad hoc efforts to change an VLI without rationalizing the VLI from established structure. Unregulated virtual positions are a means for adapting the VLI without disrupting it. They involve new task process that do not existing structure while the effort to informally handle these new task processes avoids VLI redesign. Experience is gained with the new task processes, they become better understood, expertise is identified, and after a while it may become clear how to rationalize and adjust the VLI structure to perform them. Sometimes the problem will just simply go away and the virtual position vanishes. Usually however virtual positions provide a means for informally adapting an VLI. Best unregulated virtual positions provide a sensible mechanism for adaptation which allows learning without seriously disrupting a VLI.

It takes time for the unregulated virtual position to form and to perform its adaptations. Unregulated virtual positions work well in the short run in environments where change is relatively slow. However, with rapid change, VLIs can reach the point where virtual positions are being created faster than they are absorbed. As the virtual positions accumulate, the interdependencies among them creates needs for additional virtual positions and each effort to 
informally resolve them increases the problems of managing the new inter dependency alongside the previously existing once. The result is that the VLI gradually loses its ability to respond to change. Consequently, what was an adaptive mechanism in relatively stable conditions can become maladaptive as instability increases (Boisot, M, J Child, 1999). Another symptom is the rise of incident of power struggle among officers.

\section{Virtual Positions as Arenas For Virtual Power}

Each virtual position involves at least three actors. At stake is the control of some task processes and the leverage this task process can have on others. Admittedly, each actor has the opportunity to access information with other persons. At stake is the capture of a new task process which can be used to expand the turf of actors, capture the new task processes and create new structures. And because the new task processes may involve major, recurring vulnerabilities, their control can allow an actor to control a contingent criticality and therefore increase the dependency on the expertise which can be parlayed into VLI power through virtual position. Even if an actor does not gain control of the new task processes, his actions in the virtual position allow him to at least be in the position to bargain or negotiate in arenas for power struggle within VLIs. The actors and the issues involved can be spotted through an VLI chart. But beyond examining an org chart, virtual positions represent the primal issues which are the basis for controlling VLI interdependence. The spread of virtual positions creates areas of virtual power and when that occurs, any person who is serious about work performed MUST get involved in order to protect his or her interest.

\section{Conclusions}

This paper began with a brief discussion on the topics and literature for the distribution of power in VLI as well as the critical contingencies approach. The main ideas in this literature are that power arises out of dependence by one actor on another and dependency is interwoven with uncertainty, where power is linked to the control of the uncertainties. The critical contingency theories are metaphors having heuristic values they apply a quick analysis of power and its enactment. However, the literature has a number of conceptual, empirical, and methodology problems which limits its use.

This paper postulates that there is a hierarchy of interdependence uncertainty and that power is the control of interdependence uncertainty. In this case, power can be enacted at almost any point in the VLI along with the many power enactments on different issues or simultaneous. Because of the hierarchy of interdependence uncertainty, power and task uncertainty are a level task process which we expect to become affected by power and uncertainty. It is also postulated that the analysis of power structures involves a structural analysis of an actual situation. Consequently, there are many possible and connected arenas for power struggles in VLIs of all types and those involved may not even be aware that they are engaged in a power struggle.

Virtual positions are arenas for power struggles. They meet the conditions for power enactment. They directly affect and are affected by interdependence uncertainty. Virtual positions are directly observable and provide definition of any person who is involved. the person and Is 
involved. To this end, the understand of the intangible power struggles through uncertainty is certainly worth doing.

In a 10 second soundbite? When getting a virtual position through the relevant environment, how do you obtain control, order of rollout, and power? Control or upset the nodes and edges of the network. The network will respond.

\section{References}

Ansell, C, Bichir, R, \& Zhou, S. (2016). Who Says Networks, Says Oligarchy? Oligarchies as "Rich Club" Networks. Connections - Official Journal of the International Network for Social Network Analysis, 35(2), 20-32. https://doi.org/10.17266/35.2.2

Baligh, H. H. (1986). Decision rules and transactions, organizations and markets. Management Science, 32, 11. https://doi.org/10.1287/mnsc.32.11.1480

Barry, A (2013) The Translation Zone: Between Actor-Network Theory and International Relations. Millennium Journal of International Studies, 41(3), 413-429. https://doi.org/10.1177/0305829813481007

Boisot, M, \& Child, J. (1999). Organizations as adaptive systems in complex environments: The case of China. Organization Science, 10(3), 215-376. https://doi.org/10.1287/orsc.10.3.237

Donaldson, L. (1999). The Normal Contingency Organizations: Theory and Method. Thousand Oaks, CA: Sage.

Doz, YL (1996). The evolution of cooperation in strategic alliances: initial conditions or learning processes? Strategic Management Journal, 17(S1), 1080. https://doi.org/10.1002/smj.4250171006

Keohane, RO. (1998). International institutions: Can interdependence work? International institutions: Can interdependence work? Foreign Policy, 110. https://doi.org/10.2307/1149278

Sharicz, CAZ, deToni, \& AF F Nonino. (2010). The key roles in the informal organization: a network analysis perspective. The Learning Organization, 17(1), 86-103. https://doi.org/10.1108/09696471011008260

Schoonhoven, CB. (1981). Problems with contingency theory: testing assumptions hidden within the language of contingency theory. Administrative science quarterly. https://doi.org/10.2307/2392512

Sniezek, JA, DR May, \& JE Sawyer. (1990). Social uncertainty and interdependence: A study of resource allocation decisions in groups. Organizational Behavior and Human Decision Processes, 46(2), 155-180. https://doi.org/10.1016/0749-5978(90)90027-7 